\title{
Addressing health disparities in rural communities using telehealth
}

\author{
James P. Marcin', Ulfat Shaikh' and Robin H. Steinhorn'
}

The regionalization of pediatric services has resulted in differential access to care, sometimes creating barriers to those living in underserved, rural communities. These disparities in access contribute to inferior healthcare outcomes among infants and children. We review the medical literature on telemedicine and its use to improve access and the quality of care provided to pediatric patients with otherwise limited access to pediatric subspecialty care. We review the use of telemedicine for the provision of pediatric subspecialty consultations in the settings of ambulatory care, acute and inpatient care, and perinatal and newborn care. Studies demonstrate the feasibility and efficiencies gained with models of care that use telemedicine. By providing pediatric subspecialty care in more convenient settings such as local primary care offices and community hospitals, pediatric patients are more likely to receive care that adheres to evidence-based guidelines. In many cases, telemedicine can significantly improve provider, patient, and family satisfaction, increase measures of quality of care and patient safety, and reduce overall costs of care. Models of care that use telemedicine have the potential to address pediatric specialists' geographic misdistribution and address disparities in the quality of care delivered to children in underserved communities.

\section{INTRODUCTION}

According to the 2010 Census, rural areas of the United States are home to nearly $20 \%$ of the population. As a result, many children face significant access barriers to important pediatric health services $(1,2)$. These barriers include geographic challenges for families living in rural communities, a relative shortage and maldistribution of general pediatricians and pediatric subspecialists, as well as social and economic barriers that make it difficult to travel to locations where pediatric health services are provided. Primary care pediatricians working in rural communities also report greater barriers in accessing subspeciality care compared to other providers (3). These barriers and differential access to pediatric care are at least partly to blame for disparities in health outcomes, particularly for children with special healthcare needs living in underserved, rural communities (4). Children with suboptimal access to care have been shown to more frequently forgo visits to pediatric subspecialists and to rely more heavily on the emergency department for care $(5,6)$.
A growing body of literature demonstrates that many of these access barriers can be partly addressed with the use of telemedicine (7). Models of care that use telemedicine can introduce otherwise regionalized pediatric subspecialty expertise into the most remote communities as well as nontraditional settings such as childcare centers, school, or home $(8,9)$. Services provided using telemedicine can simultaneously minimize burdens of parents and other caregivers missing work, children missing school, and costs and risks associated with travel (7,10-13).

In this review, we discuss how telemedicine can be utilized to improve the quality of care provided to children with geographically limited access to pediatric expertise and subspecialty care. After a brief overview of the different types of telemedicine and key technical aspects, we focus on successful examples and the potential for telemedicine in three clinical settings-ambulatory care, acute and inpatient care, and perinatal and newborn care (Table 1).

\section{OVERVIEW OF TELEMEDICINE}

Telemedicine is defined as the "use of electronic information and communications technologies to provide and support healthcare when distance separates the participants" (14). The term "telemedicine" is typically limited to the use of these technologies for delivery of direct patient health services. The term "telehealth," while often used interchangeably with telemedicine, is a broader term that includes telemedicine, as well as other health-related services using electronic information and communications technologies, such as health information sharing, health profession and patient education, and remote or mobile patient monitoring.

Telemedicine generally encompasses three distinct types of applications, including live interactive videoconferencing (synchronous), store-and-forward (asynchronous) transmission of medical images and/or information, and remote patient monitoring. Live telemedicine involves real-time, two-way transmission between a patient and provider and is most commonly used for ambulatory subspecialty consultations. Several studies have demonstrated that this type of care results in high-quality care, with high satisfaction rates reported by providers, patients, and caregivers (15-19). Store-and-forward telemedicine involves a specialist's review of a recorded health history with digital images or video. Common examples in pediatrics are the use

'Department of Pediatrics, University of California-Davis School of Medicine, Sacramento, California. Correspondence: James P. Marcin (jpmarcin@ucdavis.edu) Received 24 April 2015; accepted 29 June 2015; advance online publication 11 November 2015. doi:10.1038/pr.2015.192 


\section{Review Marcinetal.}

Table 1. Examples of telemedicine applications in pediatrics

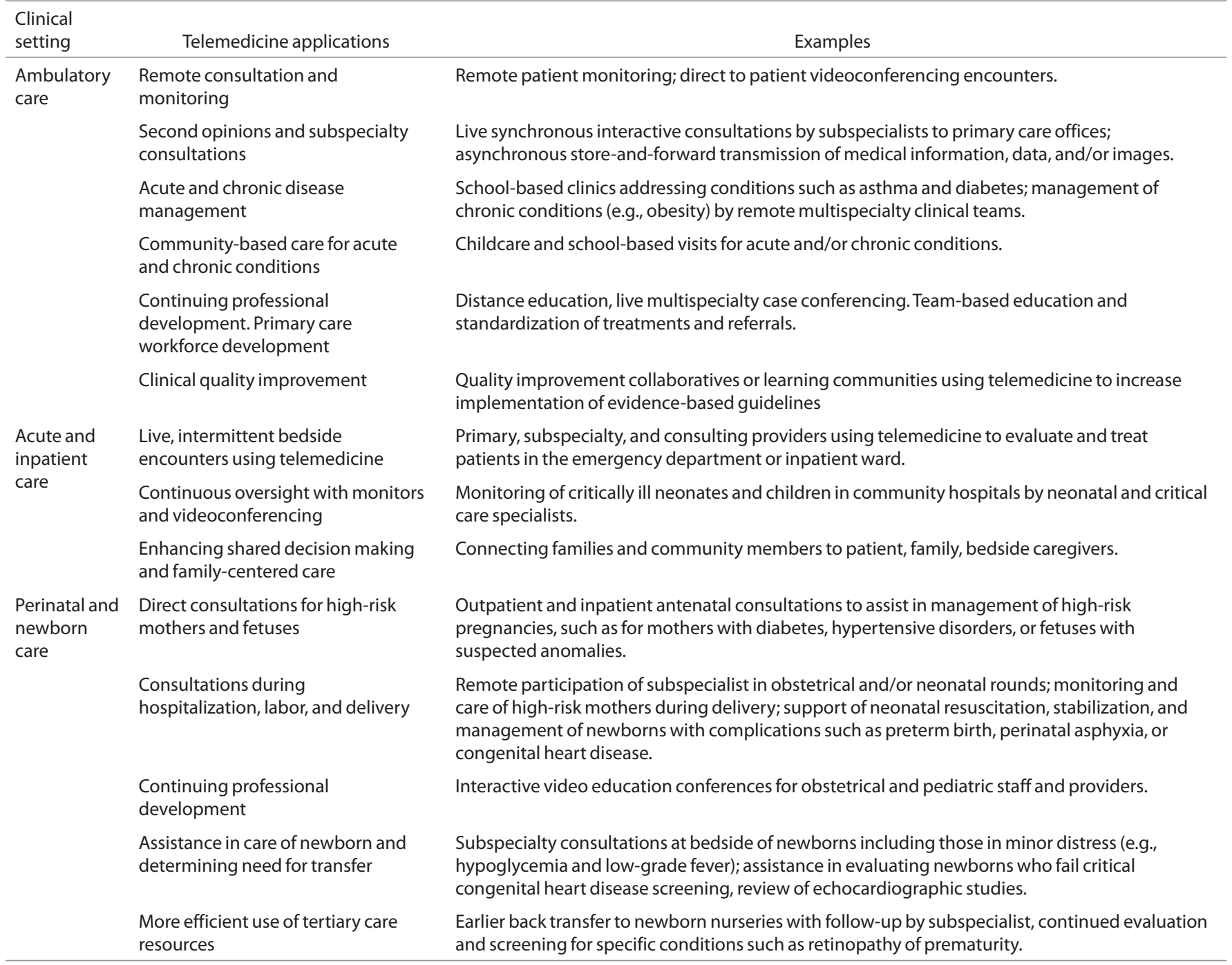

of tele-echocardiography (20-22), tele-dermatology $(23,24)$, and tele-retinal screening (25). Remote patient monitoring involves the transmission of personal health and medical data allowing a provider to track healthcare data, such as symptoms, vital signs, and/or laboratory data. Remote patient monitoring often utilizes mobile technologies and has also been shown to successfully result in care with outcomes similar to in-person outcomes for several chronic pediatric conditions, including asthma (26), diabetes (27), and obesity (28). All three of these telemedicine modalities have been used in caring for children with a variety of conditions in a variety of settings $(8,16,29-31)$.

\section{AMBULATORY CARE}

Rural populations face significant health disparities compared to urban populations (32-37). Rural residents report less access to general and specialty pediatric care, greater travel time to healthcare providers, less commercial insurance, lower likelihood of exercising, and higher rates of chronic conditions such as obesity, heart disease, and diabetes than their urban counterparts (38-41). Families living in rural areas are also at risk for low health literacy due to overall lower educational levels compared to residents in urban areas. Lower health literacy is associated with a lower likelihood of using preventive health services and overall poorer health status.

Approximately $60 \%$ of Primary Medical Health Professional Shortage Areas in the United States are located in nonmetropolitan areas. There are 40 subspecialists for every 100,000 patients in rural areas compared to 134 for every 100,000 patients in urban areas (42). These workforce shortages not only result in greater challenges for primary care providers in rural areas to providing high-quality care but also significantly limit overall access to needed healthcare services for rural residents. Unique challenges faced by rural healthcare providers include professional isolation, reduced access to medical information and continuing education, and lack of communication with subspecialists and ancillary support services $(43,44)$.

Telemedicine is taking on an increasing role in addressing these gaps in pediatric ambulatory care. Telemedicine has been successfully used in pediatric subspecialties such as dermatology, psychiatry, otolaryngology, endocrinology, pulmonary medicine, 
and cardiology and has consistently led to strong patient, caregiver, and provider satisfaction $(21,24,45-48)$. Telemedicine has also successfully reduced the costs of healthcare and time related to physician travel in addition to reducing the time and out of pocket expenses for patients and families who may need to travel from remote or hard-to-reach locations for their care (49-51). In many cases, the use of telemedicine in the ambulatory setting has reduced the need for office visits and hospitalizations, mitigated the use of emergency department for nonemergency problems, increased parent satisfaction, and enhanced effective population health management (52). Evolving reimbursement models that emphasize value-based instead of volume-based care have the potential to further contribute to the adoption of telemedicine in the ambulatory setting.

\section{Subspecialty Care}

Telemedicine can enhance access to subspecialty care for children with special healthcare needs in rural underserved areas and result in high parent and local healthcare provider satisfaction with these services (7). For example, store-and-forward and live interactive teledermatology consultations result in significant changes in diagnosis, treatment plans, and clinical outcomes. In an analysis of 1,500 live interactive teledermatology consultations in California, changes in diagnoses were made in $70 \%$ of patients and changes in management were made in $98 \%$ of patients. Among patients with more than one teledermatology visit, $\sim 70 \%$ improved clinically (53). In a study in the United Kingdom, pediatric otolaryngology consultations by telemedicine were shown to be feasible and to reduce costs by $30 \%$ when compared to face-to-face visits (54). A child telepsychiatry consult system serving publicly insured children as well as children in foster care in Wyoming reduced outliers in psychotropic medication prescribing, was well accepted by community clinicians, prevented admissions to residential treatment facilities, and reduced costs of care (19).

Another model of care that uses telehealth is one which encompasses provider education and case reviews as opposed to direct patient care. Project ECHO (Extension for Community Healthcare Outcomes) was formed to employ telemedicine more broadly to enhance chronic disease management in rural New Mexico (55). This model uses telemedicine technology to link expert specialist teams at an academic hub with primary care clinicians in local communities. Weekly teleECHO clinics combine patient case presentations with mentoring to elevate the level of care provided in remote areas. While Project ECHO was originally described in the care of patients with hepatitis $\mathrm{C}$, it has expanded to allow primary care providers and specialists to work collaboratively as a team to address a variety of chronic conditions (56).

\section{Childcare and School Settings}

Acute illness places a substantial burden on families with young children. In a recent study in upstate New York, pediatric telemedicine visits to childcare and elementary school settings significantly reduced school absence and emergency department overuse (12). Remotely connecting children with their primary care provider has the potential to enhance continuity and safety and conveniently deliver care within medical homes. In addition, parental absence from work due to their child's illness can be minimized.

Team-based management of chronic conditions can also be enhanced through school-based telemedicine. Asthma is the most prevalent pediatric chronic condition in the United States, and quality of care for asthma is increased when generalists and subspecialists work together to deliver collaborative care. Children with persistent asthma at a rural school-based health clinic treated by telemedicine visits to an asthma specialty program showed improvements in control of symptoms and quality of life that were similar to face-to-face encounters with subspecialists (57). Telemedicine has also improved care of children with type 1 diabetes within school nurse offices. In a study of school-centered telemedicine for children in grades kindergarten through eighth grade, school nurses, children, and the clinical diabetes team engaged in monthly videoconferencing using a telemedicine unit in the school nurse's office. The intervention showed improvements in hemoglobin A1c as well as pediatric quality of life. There were fewer urgent calls for diabetes care by the school nurse, as well as reductions in emergency department visits and hospital admissions (58).

\section{Primary Care Workforce Development}

Rural areas have fewer physicians, nurses, and specialists, and it is projected that rural workforce shortages will increase even more in the future (59). In California, the number of pediatric subspecialists in rural areas is $80-90 \%$ lower than that for urban areas such as San Francisco and Los Angeles. Given lower access to specialists, rural primary care clinicians perform a higher volume and variety of procedures compared to clinicians in urban areas. Despite their need for a broader range of competencies, rural clinicians face several challenges related to continuing professional development, including travel time, expense, and geographic isolation. Distance education delivered using telehealth technologies can overcome several of these barriers. Delivery methods for continuing education may include videoconferencing with subspecialists, web-based education, and live Internet case conferencing (60).

In addition to providing individual-level education, telemedicine can connect rural clinics and hospitals for collaborative quality improvement and extend educational opportunities to bring in evidence-based guidelines into practice within the rural medical home (61). Over the past three decades, the prevalence of obesity has more than doubled for children aged 2 to $5 \mathrm{y}$ and has tripled for children aged 6-11 y (62). Participation in a virtual professional community, the Healthy Eating Active Living Telehealth Community of Practice (HEALTH COP), increased assessment of weight status and counseling for diet and physical activity by clinicians in rural clinics and improved children's health behaviors (63).

\section{ACUTE AND INPATIENT CARE}

The use of telemedicine to provide pediatric specialty consultations and assistance in the care of seriously ill children in 


\section{Review | Marcinetal.}

emergency departments and inpatient hospital units is on the rise. Recent studies suggest that the use of live videoconferencing can result in higher quality of care than the current standard of case discussion using the telephone. In general, the benefit of using telemedicine instead of traditional telephone communication is that the pediatric specialist can have a virtual presence at the patient's bedside. The consultant has direct access to high-definition patient views, the team of treating providers, the family, as well as monitors and equipment.

\section{Emergency Department}

There is increased acceptance and evidence that the use of telemedicine to provide pediatric consultations to remote emergency departments results in similar diagnoses, treatment plans, and plans for disposition as in-person pediatric consultations (64-70). Published literature from two programs describes how pediatric subspecialists, primarily pediatric critical care physicians, use telemedicine to provide consultations to critically ill children presenting to a network of rural emergency departments (66,70). Heath et al. (66), at the University of Vermont, reviewed $2 \mathrm{y}$ of data where a program provides virtual consultations to 10 rural emergency departments and concluded that use of telemedicine was associated with improved patient care compared to telephone consultations.

Several analyses of consultations to rural emergency departments from the University of California, Davis, have found that parents and remote providers are more satisfied and more frequently modify diagnoses and/or therapeutic interventions when telemedicine is used compared to the telephone $(71,72)$. Using a structured implicit review process, these researchers also found that patients receiving telemedicine consultations in remote emergency departments received higher overall quality of care compared to similar patients receiving telephone consultations $(71,72)$. In addition, in a separate analysis of different emergency departments participating in this telemedicine network, researchers found that the frequency of medication errors was significantly lower (3.4\%) than the rate of medication errors among children receiving telephone consultations (10.8\%) and when no consultations were obtained (12.5\%) (73). Finally, when the appropriateness of interfacility transfers were evaluated using previously validated pediatric emergency medicine prediction models, researchers found that the use of telemedicine resulted in more appropriate rates of admissions, specifically reducing the frequency of admission for children who could be managed in an ambulatory or local hospital setting (74).

In summary, there is mounting evidence that pediatric subspecialty consultations to underserved, rural emergency departments using telemedicine can be used to help address disparities in access to specialists, and in doing so, improve the overall satisfaction, safety, quality, and effectiveness of care.

\section{Inpatient Care Units}

Clinicians caring for moderately ill children in rural communities must often decide whether or not to admit locally to keep patients and families in their own community or to transfer to a regional pediatric hospital. Sometimes, pediatric patients and their families are subjected to lengthy and risky transports because of a systematic tendency to "over-triage" children because of the potential need for pediatric specialty services (75). In fact, the transfer of some pediatric patients to a pediatric referral center is often not necessary if there is a closer hospital with adequate pediatric capabilities, such as a pediatric ward or intermediate pediatric or neonatal intensive care unit (NICU) with pediatric expertise $(76,77)$.

There is mounting evidence that caring for less severely ill children in local or nonregional children's hospital centers can still result in high quality of care and can be done so with shorter length of stays, less resource utilization, and lower costs (78-80). It is therefore logical that some of these children can be cared for in community hospitals under the care of local pediatric nurses and physicians with supervision using telemedicine from pediatric specialists at a regionalized pediatric referral center.

Examples of this model of care include programs where pediatric subspecialists provide consultations and supervision of care to hospitalized children in a variety of clinical scenarios, including inpatient wards and neonatal and general intensive care units (81-85). Physician consultations, nurse and physician monitoring, and medical oversight can range from a simple model of intermittent, need-based consultations (consultative model), to a model that integrates continuous monitoring and proactive medical decision making (continuous oversight model) (86). In the consultative model, pediatric subspecialists are able to provide intermittent, bedside telemedicine consultations to a patient hospitalized in a remote inpatient ward, high-acuity unit, or general intensive care unit. Such consultations could prompt a variety of clinical interventions, including recommendations on diagnostic studies, medications, or other therapies. The consultation may also conclude with a timely transport of the patient to the regional Pediatric intensive care unit.

This telemedicine model has also been used to assist in the care of critically ill children hospitalized in other countries (87-89). The Children's Hospital of Pittsburgh has had a longstanding relationship with four hospitals in Latin America, including a cardiac intensive care unit (88). Similar to study findings from the United States, the use of telemedicine has contributed to very high perceptions of satisfaction, usefulness, and impact on medical practice (89), as well as reductions in length of stay (87).

\section{PERINATAL AND NEWBORN CARE}

Telemedicine has begun to emerge as a strategy to enhance the quality and efficiency of care for perinatal and newborn care in the rural setting. Approximately 10 to $12 \%$ of all newborn infants are admitted to NICUs for specialized care. While regionalized perinatal and neonatal intensive care has been shown to reduce neonatal mortality, birth at a regional center is often difficult to achieve because complications of pregnancy and delivery such as preterm birth, hypoxic-ischemic encephalopathy, and genetic anomalies often present suddenly 
without warning. Telemedicine can be used by maternal-fetal medicine specialists to direct care of high-risk mothers and fetuses, assist in the monitoring and care of the delivery, and help in the immediate management of newborns.

Antenatal management of high-risk pregnancies from a distance has been accomplished for conditions ranging from maternal diabetes, hypertensive disorders, cervical insufficiency, and suspected fetal anomalies, including congenital heart disease (90-92). In Arkansas, telemedicine-supported care in the rural setting has been shown to reduce the need for in-person visits (where the mother would have to travel to the tertiary center) by nearly $50 \%$, while maintaining the appropriate utilization of maternal-fetal medicine subspecialty consultations (91). Studies evaluating the use of antenatal management using telemedicine have found that collaborations between a subspecialty perinatal referral hospital, and hospitals lacking neonatologists successfully reduced the number and proportion of very-low-birth-weight births at these facilities $(93,94)$. With regard to fetal telecardiology, other researchers have demonstrated that remote diagnostic evaluations and parental counseling can be done accurately and are well accepted by providers and families (95-97).

Another program from the University of Arkansas uses telemedicine to conduct twice weekly obstetrical census rounds, provide 24/7 access to obstetrical and neonatal telemedicine consultations, thrice weekly neonatal rounds, and thrice weekly interactive video education conferences for obstetrics and pediatrics. This resource-intensive model, relying on videoconferencing between obstetrical and neonatal teams, significantly reduced the deliveries of very-low-birth-weight infants in nine participating hospitals without NICUs from 13.1 to $7.0 \%$ (94). This finding is important because the researchers simultaneously found a concurrent and statistically significant reduction in statewide infant mortality. The authors conclude that use of a telemedicine program to improve perinatal outcomes led to a decrease in very-low-birth-weight births in hospitals without NICUs and was associated with an overall decrease in statewide infant mortality.

In addition to elevating the level of antenatal care, telemedicine has begun to emerge as a mechanism to support neonatal resuscitation in remote sites and to improve the care, transfer times, and initiation of neuroprotective cooling after perinatal asphyxia (98). In a rural setting, neonatal resuscitations are typically attended by general pediatricians or family practitioners. Telemedicine-supported education can be used to complete standard Neonatal Resuscitation Program training and has been reported to produce comparable gains in knowledge and skills relative to in-person training (99). While Neonatal Resuscitation Program is a highly reliable method to gain initial competency in delivery room resuscitation, knowledge and technical competency rates decline within 6 mo if the skills are not used (100). Furthermore, delivery volumes are low in small hospitals, and the need for advanced neonatal resuscitation is a rare event, occurring in less than $1 \%$ of all births. Because of this need to maintain high proficiency in the face of low volumes, rural providers face inevitable challenges in maintaining competence in resuscitation. A program in Oregon recently reported the use of telemedicine units in the delivery room to provide immediate, direct access to skilled resuscitators as needed. This system connects a rural physician or nurse with a nurse practitioner or physician in the central site and has been activated in $\sim 2 \%$ of the births at the remote sites (98). Event tracking has revealed that the remote providers are able to maintain a calmer environment, and additional benefits may include reducing the time to initiation of transfer and therapeutic hypothermia.

Telemedicine can also provide the subspecialty expertise needed to determine whether a baby can remain at the rural hospital or whether transfer is necessary to accomplish additional evaluation. For example, critical congenital heart disease (CCHD) was added to the Recommended Uniform Screening Panel for Newborns in the United States in 2011 (101), and more than $80 \%$ of states now require universal CCHD screening by pulse oximetry in the birth hospital. Current literature predicts that 2-3 out of every 1,000 newborns will have a positive CCHD screen, which introduces special challenges in the rural setting. While the false-positive rate for pulse oximetry testing is high, particularly when the screening is done prior to $24 \mathrm{~h}$ of age, a positive test requires rapid access to a diagnostic echocardiogram and, in some cases, evaluation by a pediatric cardiologist. For those newborns delivered at rural hospitals that fail CCHD screening, telemedicine could improve diagnostic accuracy following a positive screen through training of echocardiography technicians, asynchronous or concurrent review of echo images, and remote viewing of the infant.

Finally, although delivery in a centralized regional NICU has been shown to improve outcomes for critically ill neonates (102), families pay a personal cost when their infant is hospitalized far from home. As telemedicine becomes easier to implement using personal computers, pilot studies in California and Utah have reported linking families by remote access to bedside rounds and nursing caregivers. Telemedicine may also allow for earlier transfer back to a rural step-down nursery by providing telemedicine screening for specific conditions such as retinopathy of prematurity (25).

\section{CONCLUSIONS}

Regionalization of pediatric services not only is associated with increased efficiency and improved outcomes for some conditions but has also resulted in differential access to care, creating barriers for many children, particularly those living in rural and underserved communities. The use of telemedicine to provide acute ambulatory and subspecialty care, acute inpatient care, and perinatal and newborn care is now emerging as a feasible and efficient strategy that results in high-quality cost-effective care. Several studies have demonstrated that by using telemedicine to provide direct patient care or support the care of children in local primary care and hospital settings, pediatric patients are more likely to receive care consistent with evidence-based guidelines, as well as more appropriate referrals to subspecialists. Telemedicine is increasingly becoming integrated into standard practice across a broad range of 


\section{Review Marcin et al.}

healthcare services, particularly in states that serve large rural populations. Given the growth of telemedicine, a broad research agenda that focuses on metrics and includes translational research, community-based participatory research, and public health research is needed. As the technologies continue to evolve, telemedicine has the potential to address pediatric specialists' geographic misdistribution, and the associated disparities in the access to care for children in underserved communities.

\section{STATEMENT OF FINANCIAL SUPPORT}

No financial support was provided for this manuscript

Disclosure: The authors have nothing to disclose.

\section{REFERENCES}

1. Randolph GD, Pathman DE. Trends in the rural-urban distribution of general pediatricians. Pediatrics 2001;107:E18.

2. Basco WT, Rimsza ME; Committee on Pediatric Workforce; American Academy of Pediatrics. Pediatrician workforce policy statement. Pediatrics 2013;132:390-7.

3. Pletcher BA, Rimsza ME, Cull WL, Shipman SA, Shugerman RP, O'Connor KG. Primary care pediatricians' satisfaction with subspecialty care, perceived supply, and barriers to care. J Pediatr 2010;156:1011-5, 1015.e1.

4. Skinner AC, Slifkin RT. Rural/urban differences in barriers to and burden of care for children with special health care needs. J Rural Health 2007;23:150-7.

5. Johnson WG, Rimsza ME. The effects of access to pediatric care and insurance coverage on emergency department utilization. Pediatrics 2004;113:483-7.

6. Ray KN, Bogen DL, Bertolet M, Forrest CB, Mehrotra A. Supply and utilization of pediatric subspecialists in the United States. Pediatrics 2014;133:1061-9.

7. Marcin JP, Ellis J, Mawis R, Nagrampa E, Nesbitt TS, Dimand RJ. Using telemedicine to provide pediatric subspecialty care to children with special health care needs in an underserved rural community. Pediatrics 2004;113:1-6.

8. Herendeen N, Deshpande P. Telemedicine and the patient-centered medical home. Pediatr Ann 2014;43:e28-32.

9. McConnochie KM, Conners GP, Brayer AF, et al. Effectiveness of telemedicine in replacing in-person evaluation for acute childhood illness in office settings. Telemed J E Health 2006;12:308-16.

10. Uscher-Pines L, Mehrotra A. Analysis of Teladoc use seems to indicate expanded access to care for patients without prior connection to a provider. Health Aff (Millwood) 2014;33:258-64.

11. McConnochie KM. Potential of telemedicine in pediatric primary care. Pediatr Rev 2006;27:e58-65.

12. McConnochie KM, Wood NE, Herendeen NE, ten Hoopen CB, Roghmann KJ. Telemedicine in urban and suburban childcare and elementary schools lightens family burdens. Telemed J E Health 2010;16:533-42.

13. McConnochie KM, Wood NE, Kitzman HJ, Herendeen NE, Roy J, Roghmann KJ. Telemedicine reduces absence resulting from illness in urban child care: evaluation of an innovation. Pediatrics 2005;115:1273-82.

14. Institute of Medicine. Telemedicine: A Guide to Assessing Telecommunications for Health Care. Washington, D.C.: Natinoal Academy Press, 1996.

15. Marcin J, Ellis J, Mawis R, Nagrampa E, Nesbitt T, Dimand R. Telemedicine and the medical home: providing pediatric subspecialty care to children with special health care needs in an underserved rural community. Pediatrics 2003;113:1-6.

16. Marcin JP, Trujano J, Sadorra C, Dharmar M. Telemedicine in rural pediatric care: the fundamentals. Pediatr Ann 2009;38:224-6.

17. Farmer JE, Muhlenbruck L. Telehealth for children with special health care needs: promoting comprehensive systems of care. Clin Pediatr (Phila) 2001;40:93-8.
18. Karp WB, Grigsby RK, McSwiggan-Hardin M, et al. Use of telemedicine for children with special health care needs. Pediatrics 2000;105:843-7.

19. Hilt RJ, Barclay RP, Bush J, Stout B, Anderson N, Wignall JR. A statewide child telepsychiatry consult system yields desired health system changes and savings. Telemed J E Health 2015;21:533-7.

20. Webb CL, Waugh CL, Grigsby J, et al.; American Society of Echocardiography Telemedicine Collaborators' Group. Impact of telemedicine on hospital transport, length of stay, and medical outcomes in infants with suspected heart disease: a multicenter study. J Am Soc Echocardiogr 2013;26:1090-8.

21. Sable C. Telemedicine applications in pediatric cardiology. Minerva Pediatr 2003;55:1-13.

22. Sable C. Digital echocardiography and telemedicine applications in pediatric cardiology. Pediatr Cardiol 2002;23:358-69.

23. Philp JC, Frieden IJ, Cordoro KM. Pediatric teledermatology consultations: relationship between provided data and diagnosis. Pediatr Dermatol 2013;30:561-7.

24. Fogel AL, Teng JM. Pediatric teledermatology: a survey of usage, perspectives, and practice. Pediatr Dermatol 2015;32:363-8.

25. Fierson WM, Capone A Jr; American Academy of Pediatrics Section on Ophthalmology; American Academy of Ophthalmology, American Association of Certified Orthoptists. Telemedicine for evaluation of retinopathy of prematurity. Pediatrics 2015;135:e238-54.

26. Chan DS, Callahan CW, Hatch-Pigott VB, et al. Internet-based home monitoring and education of children with asthma is comparable to ideal officebased care: results of a 1-year asthma in-home monitoring trial. Pediatrics 2007;119:569-78.

27. Recupero A, Mahnke B, Pinsker JE. Emerging technology in diabetes care: the real-time diabetes monitoring system. Mil Med 2013;178:218-21.

28. Shaikh U, Cole SL, Marcin JP, Nesbitt TS. Clinical management and patient outcomes among children and adolescents receiving telemedicine consultations for obesity. Telemed J E Health 2008;14:434-40.

29. Herendeen NE, Schaefer GB. Practical applications of telemedicine for pediatricians. Pediatr Ann 2009;38:567-9.

30. McSwain SD, Marcin JP. Telemedicine for the care of children in the hospital setting. Pediatr Ann 2014;43:e44-9.

31. North SW, McElligot J, Douglas G, Martin A. Improving access to care through the patient-centered medical home. Pediatr Ann 2014;43:e33-8.

32. Dower C, McRee T, Grumbach K, et al. The Practice of Medicine in California: A Profile of the Physician Workforce. San Francisco, CA: California Workforce Initiative at the UCSF Center for the Health Professions, 2001.

33. Merwin E, Snyder A, Katz E. Differential access to quality rural healthcare: professional and policy challenges. Fam Community Health 2006;29:186-94.

34. Cull WL, Chang CH, Goodman DC. Where do graduating pediatric residents seek practice positions? Ambul Pediatr 2005;5:228-34.

35. Hartley D. Rural health disparities, population health, and rural culture. Am J Public Health 2004;94:1675-8.

36. Eberhardt M, Ingram D, Makuc D. Health, United States, 2001. Urban and Rural Health Chartbook. Hyattsville, MD: National Center for Health Statistics, 2001

37. Eberhardt MS, Pamuk ER. The importance of place of residence: examining health in rural and nonrural areas. Am J Public Health 2004;94:1682-6.

38. US Department of Health and Human Services - Health Resources and Services Administration - Maternal and Child Health Bureau. The Health and Well-Being of Children in Rural Areas: A Portrait of the Nation. Rockville, MD: US Department of Health and Human Services, 2005.

39. Levey LM, Curry JP, Levey S. Rural-urban differences in access to Iowa child health services. J Rural Health 1988;4:59-72.

40. Saywell RM Jr, Zollinger TW, Schafer ME, Schmit TM, Ladd JK. Children with special health care needs program: urban/rural comparisons. J Rural Health 1993;9:314-25.

41. Bolin JN, Bellamy GR, Ferdinand AO, et al. Rural healthy people 2020: new decade, same challenges. J Rural Health 2015;31:326-33.

42. U.S. Department of Health and Human Services. Detailed Health Professional Shortage Area (HPSA) Report for Primary Medical Care, 2015. (http://datawarehouse.hrsa.gov/HGDWReports/RT_App. aspx?rpt=H1). 
43. Anderson EA, Bergeron D, Crouse BJ. Recruitment of family physicians in rural practice. Minn Med 1994;77:29-32.

44. Conte SJ, Imershein AW, Magill MK. Rural community and physician perspectives on resource factors affecting physician retention. J Rural Health 1992;8:185-96.

45. Callahan EJ, Hilty DM, Nesbitt TS. Patient satisfaction with telemedicine consultation in primary care: comparison of ratings of medical and mental health applications. Telemed J 1998;4:363-9.

46. Pacht ER, Turner JW, Gailiun M, et al. Effectiveness of telemedicine in the outpatient pulmonary clinic. Telemed J 1998;4:287-92.

47. Marcin JP, Nesbitt TS, Cole SL, et al. Changes in diagnosis, treatment, and clinical improvement among patients receiving telemedicine consultations. Telemed J E Health 2005;11:36-43.

48. Pesämaa L, Ebeling H, Kuusimäki ML, Winblad I, Isohanni M, Moilanen I. Videoconferencing in child and adolescent telepsychiatry: a systematic review of the literature. J Telemed Telecare 2004;10:187-92.

49. Kumar S, Tay-Kearney ML, Chaves F, Constable IJ, Yogesan K. Remote ophthalmology services: cost comparison of telemedicine and alternative service delivery options. J Telemed Telecare 2006;12:19-22.

50. Samii A, Ryan-Dykes P, Tsukuda RA, Zink C, Franks R, Nichol WP. Telemedicine for delivery of health care in Parkinson's disease. J Telemed Telecare 2006;12:16-8.

51. Malasanos TH, Burlingame JB, Youngblade L, Patel BD, Muir AB. Improved access to subspecialist diabetes care by telemedicine: cost savings and care measures in the first two years of the FITE diabetes project. J Telemed Telecare 2005;11:Suppl 1:74-6.

52. McConnochie KM, Wood NE, Herendeen NE, et al. Acute illness care patterns change with use of telemedicine. Pediatrics 2009;123:e989-95.

53. Lamel S, Chambers CJ, Ratnarathorn M, Armstrong AW. Impact of live interactive teledermatology on diagnosis, disease management, and clinical outcomes. Arch Dermatol 2012;148:61-5.

54. Xu CQ, Smith AC, Scuffham PA, Wootton R. A cost minimisation analysis of a telepaediatric otolaryngology service. BMC Health Serv Res 2008;8:30.

55. Arora S, Thornton K, Murata G, et al. Outcomes of treatment for hepatitis C virus infection by primary care providers. N Engl J Med 2011;364: 2199-207.

56. Arora S, Kalishman S, Dion D, et al. Partnering urban academic medical centers and rural primary care clinicians to provide complex chronic disease care. Health Aff (Millwood) 2011;30:1176-84.

57. Romano MJ, Hernandez J, Gaylor A, Howard S, Knox R. Improvement in asthma symptoms and quality of life in pediatric patients through specialty care delivered via telemedicine. Telemed J E Health 2001;7:281-6.

58. Izquierdo R, Morin PC, Bratt K, et al. School-centered telemedicine for children with type 1 diabetes mellitus. J Pediatr 2009;155:374-9.

59. Burrows E, Suh R, Hamann D. Health Care Workforce Distribution and Shortage Issues in Rural America 2012. (http://www.ruralhealthweb.org/ index.cfm?objectid=3D776162-3048-651A-FEA70F1F09670B0D).

60. Shaikh U, Nettiksimmons J, Romano P. Pediatric obesity management in rural clinics in California and the role of telehealth in distance education. J Rural Health 2011;27:263-9.

61. Gagnon MP, Duplantie J, Fortin JP, Landry R. Implementing telehealth to support medical practice in rural/remote regions: what are the conditions for success? Implement Sci 2006;1:18.

62. US Institute of Medicine. Preventing Childhood Obesity - Health in the Balance. Washington, D.C.: US Institute of Medicine, 2005.

63. Shaikh U, Nettiksimmons J, Joseph JG, Tancredi D, Romano PS. Collaborative practice improvement for childhood obesity in rural clinics: the Healthy Eating Active Living Telehealth Community of Practice (HEALTH COP). Am J Med Qual 2014;29:467-75.

64. Brennan JA, Kealy JA, Gerardi LH, et al. Telemedicine in the emergency department: a randomized controlled trial. J Telemed Telecare 1999;5: $18-22$.

65. Kofos D, Pitetti R, Orr R, Thompson A. Telemedicine in pediatric transport: a feasibility study. Pediatrics 1998;102:E58.

66. Heath B, Salerno R, Hopkins A, Hertzig J, Caputo M. Pediatric critical care telemedicine in rural underserved emergency departments. Pediatr Crit Care Med 2009;10:588-91.
67. Meyer BC, Raman R, Hemmen T, et al. Efficacy of site-independent telemedicine in the STRokE DOC trial: a randomised, blinded, prospective study. Lancet Neurol 2008;7:787-95.

68. Demaerschalk BM, Raman R, Ernstrom K, Meyer BC. Efficacy of telemedicine for stroke: pooled analysis of the Stroke Team Remote Evaluation Using a Digital Observation Camera (STRokE DOC) and STRokE DOC Arizona telestroke trials. Telemed J E Health 2012;18:230-7.

69. Ellenby MS, Marcin JP. The role of telemedicine in pediatric critical care. Crit Care Clin 2015;31:275-90.

70. Uscher-Pines L, Kahn JM. Barriers and facilitators to pediatric emergency telemedicine in the United States. Telemed J E Health 2014;20:990-6.

71. Dharmar M, Marcin JP, Kuppermann N, et al. A new implicit review instrument for measuring quality of care delivered to pediatric patients in the emergency department. BMC Emerg Med 2007;7:13.

72. Dharmar M, Romano PS, Kuppermann N, et al. Impact of critical care telemedicine consultations on children in rural emergency departments. Crit Care Med 2013;41:2388-95.

73. Dharmar M, Kuppermann N, Romano PS, et al. Telemedicine consultations and medication errors in rural emergency departments. Pediatrics 2013;132:1090-7.

74. Yang NH, Dharmar M, Kuppermann N, et al. Appropriateness of disposition following telemedicine consultations in rural emergency departments. Pediatr Crit Care Med 2015;16:e59-64.

75. Wakefield DS, Ward M, Miller T, et al. Intensive care unit utilization and interhospital transfers as potential indicators of rural hospital quality. J Rural Health 2004;20:394-400.

76. Rosenberg DI, Moss MM; American College of Critical Care Medicine of the Society of Critical Care Medicine. Guidelines and levels of care for pediatric intensive care units. Crit Care Med 2004;32:2117-27.

77. Walls TA, Chamberlain JM, Klein BL. Factors associated with emergency department discharge after pediatric interhospital transport: a role for outreach education? Pediatr Emerg Care 2015;31:10-4.

78. Merenstein D, Egleston B, Diener-West M. Lengths of stay and costs associated with children's hospitals. Pediatrics 2005;115:839-44.

79. Odetola FO, Gebremariam A, Freed GL. Patient and hospital correlates of clinical outcomes and resource utilization in severe pediatric sepsis. Pediatrics 2007;119:487-94.

80. Gupta RS, Bewtra M, Prosser LA, Finkelstein JA. Predictors of hospital charges for children admitted with asthma. Ambul Pediatr 2006;6:15-20.

81. Dharmar M, Smith AC, Armfield NR, Trujano J, Sadorra C, Marcin JP. Telemedicine for children in need of intensive care. Pediatr Ann 2009;38:562-6.

82. Labarbera JM, Ellenby MS, Bouressa P, Burrell J, Flori HR, Marcin JP. The impact of telemedicine intensivist support and a pediatric hospitalist program on a community hospital. Telemed J E Health 2013;19:760-6.

83. Marcin JP. Telemedicine in the pediatric intensive care unit. Pediatr Clin North Am 2013;60:581-92.

84. Marcin JP, Schepps DE, Page KA, Struve SN, Nagrampa E, Dimand RJ. The use of telemedicine to provide pediatric critical care consultations to pediatric trauma patients admitted to a remote trauma intensive care unit: a preliminary report. Pediatr Crit Care Med 2004;5:251-6.

85. Marcin JP, Nesbitt TS, Kallas HJ, Struve SN, Traugott CA, Dimand RJ. Use of telemedicine to provide pediatric critical care inpatient consultations to underserved rural Northern California. J Pediatr 2004;144:375-80.

86. Reynolds HN, Rogove H, Bander J, McCambridge M, Cowboy E, Niemeier M. A working lexicon for the tele-intensive care unit: we need to define tele-intensive care unit to grow and understand it. Telemed J E Health 2011;17:773-83.

87. Lopez-Magallon AJ, Otero AV, Welchering N, et al. Patient outcomes of an international telepediatric cardiac critical care program. Telemed J E Health 2015;21:601-10.

88. Munoz RA, Burbano NH, Motoa MV, Santiago G, Klevemann M, Casilli J. Telemedicine in pediatric cardiac critical care. Telemed J E Health 2012;18:132-6.

89. Otero AV, Lopez-Magallon AJ, Jaimes D, et al. International telemedicine in pediatric cardiac critical care: a multicenter experience. Telemed J E Health 2014;20:619-25. 
90. Ivey TL, Hughes D, Dajani NK, Magann EF. Antenatal management of at-risk pregnancies from a distance. Aust N Z J Obstet Gynaecol 2015;55: 87-9.

91. Magann EF, Bronstein J, McKelvey SS, Wendel P, Smith DM, Lowery CL. Evolving trends in maternal fetal medicine referrals in a rural state using telemedicine. Arch Gynecol Obstet 2012;286:1383-92.

92. Krishnan A, Fuska M, Dixon R, Sable CA. The evolution of pediatric tele-echocardiography: 15-year experience of over 10,000 transmissions. Telemed J E Health 2014;20:681-6.

93. Hall-Barrow J, Hall RW, Burke BL Jr. Telemedicine and neonatal regionalization of care - ensuring that the right baby gets to the right nursery. Pediatr Ann 2009;38:557-61.

94. Kim EW, Teague-Ross TJ, Greenfield WW, Keith Williams D, Kuo D, Hall RW. Telemedicine collaboration improves perinatal regionalization and lowers statewide infant mortality. J Perinatol 2013;33:725-30.

95. McCrossan BA, Sands AJ, Kileen T, Doherty NN, Casey FA. A fetal telecardiology service: patient preference and socio-economic factors. Prenat Diagn 2012;32:883-7.

96. Adriaanse BM, Tromp CH, Simpson JM, et al. Interobserver agreement in detailed prenatal diagnosis of congenital heart disease by telemedicine using four-dimensional ultrasound with spatiotemporal image correlation. Ultrasound Obstet Gynecol 2012;39:203-9.

97. McCrossan BA, Sands AJ, Kileen T, Cardwell CR, Casey FA. Fetal diagnosis of congenital heart disease by telemedicine. Arch Dis Child Fetal Neonatal Ed 2011;96:F394-7.

98. Scheans P. Telemedicine for neonatal resuscitation. Neonatal Netw 2014;33:283-7.

99. Jain A, Agarwal R, Chawla D, Paul V, Deorari A. Tele-education vs classroom training of neonatal resuscitation: a randomized trial. J Perinatol 2010;30:773-9.

100. Trevisanuto D, Ferrarese P, Cavicchioli P, Fasson A, Zanardo V, Zacchello F. Knowledge gained by pediatric residents after neonatal resuscitation program courses. Paediatr Anaesth 2005;15:944-7.

101. Peterson C, Ailes E, Riehle-Colarusso T, et al. Late detection of critical congenital heart disease among US infants: estimation of the potential impact of proposed universal screening using pulse oximetry. JAMA Pediatr 2014;168:361-70.

102. Lorch SA, Baiocchi M, Ahlberg CE, Small DS. The differential impact of delivery hospital on the outcomes of premature infants. Pediatrics 2012;130:270-8. 